\title{
Risk-Based Design for Slurry Launders
}

\author{
R.H.A. Janssen Bechtel Chile Ltda, Chile
}

\begin{abstract}
A risk-based design approach using the principles of Six Sigma, has been applied to the design of open channel launders used to convey slurry in mineral processing plants. The variability in design input parameters was defined using a triangular probability distribution for the minimum, normal and maximum design values. Measured operating data, and results based on this measured data, were then compared to the risk-based results to assess the reliability of the risk-based approach. Where the operating data has a single most likely value, the triangular distribution was found to correctly capture the variation to be used in a risk-based analysis. However, where the operating data had a more complex distribution, this was not correctly captured in the usual design criteria of minimum, normal and maximum values. More detail, based on operational simulations or measured data from previous similar projects, should therefore be used in defining the system design criteria. The results presented here demonstrate the importance of collecting data to correctly define the variation of the input parameters for a risk-based analysis.

In spite of not capturing the detailed shape of the measured data, the results of the risk-based design approach still provided a reasonable general description of the potential variation in design output. This can be used in making risk-based decisions for design, operating procedures, and capital investments.
\end{abstract}

\section{Introduction}

Open channel launders are used in mineral processing plants to convey crushed material (ore, product, or waste) as slurry. Launders are sized based on design operating conditions, but are notoriously subjected to a wide range of conditions, such as variations in solids throughput, particle size, and/or concentration. Variations may result from a normal range of operating scenarios, or from upset conditions. Launders are typically designed to meet open channel flow hydraulic criteria and minimum transport velocities to maintain particles in motion. Failing to meet these criteria can result in a combination of solids deposition (sanding), unsteady flow conditions (surging), or rapidly-varied flow conditions (standing waves and hydraulic jumps). These can all lead to overtopping, and hence operating failure, of the launder.

Therefore, launder design and operation should take into account not only design operating conditions, but also risk of failure due to deviations from these conditions. In evaluating the risks associated with a potential failure of launder operation, designers need to address the likelihood of failure, the consequence of failure, and the ability (or lack thereof) of detecting conditions leading to failure.

This paper describes a risk-based approach for design of slurry launders that assesses the variability in design input parameters using a triangular probability distribution for the realistically expected maximum, minimum, and best estimate values. Measured operating data, and results based on this measured data, are then compared to the risk-based results to establish the reliability of the risk-based approach.

\section{Risk-based design}

\subsection{Background}

The typical approach in engineering design is to establish design values for input parameters based on expected operating conditions, previous experience, or design guides, resulting in a single design operating point. Worst case operation is similarly evaluated by combining an extreme for each of the input parameters. This deterministic approach has a major drawback in that it does not provide any indication of the potential variability in the output due to variations (or combinations thereof) in the input. By not assessing the potential for excursions from the design conditions, designers are not fully evaluating the risk of the system not meeting its performance criteria. 
However, stakeholders are insisting on a more systematic and accountable approach to risk analysis, to form the basis for risk management and capital investment decisions. By considering risk of failure as a quality issue, Six Sigma was used to develop a risk-based design approach, which was then applied to the slurry launder design case.

\subsection{Failure modes effects analysis}

Six Sigma (Pyzdek, 2003) has been adopted by organisations worldwide to manage quality. Six Sigma applies a number of rigorous approaches to identify and quantify sources of variation in processes. One such approach, Failure Mode Effects Analysis (FMEA), is used to evaluate possible failure modes in a process. For an identified failure event, scores of 1 to 10 are assigned to the severity, likelihood, and detectability of the event. A combined Risk Profile Number (RPN) for that particular failure mode is computed.

$$
\text { RPN = Severity } x \text { Likelihood } x \text { Detectability }
$$

The last of the three aspects, the detectability and hence possible avoidance of a potential failure event has generally not considered in risk analysis in the past. However, instrumentation or inspection routines can be incorporated in many system designs to help reduce the associated risk by identifying problems before they occur.

Janssen (2007) showed that risk-based design could be applied to design of slurry launders by comparing a base case design with a rectangular open channel launder, two enhancements to the base case, and an alternate pipe launder design. The enhancements to the base case showed promising improvements to the RPN without high capital costs but presented operational limitations. The pipe launder option had the lowest RPN of all alternatives, which provided justification for its selection as the preferred option in spite of a higher capital cost. RPN ratings for severity, likelihood, and detectability based on standard Six Sigma guidelines allowed stakeholders to assess the risk criteria using a common benchmark.

The first step in risk-based design is to clearly identify the risk parameters associated with the system being designed.

\subsection{Risk parameters}

\subsubsection{Input variability}

Risk originates from variability associated with input to a design of a system. Janssen (2005) identified the following two sources of input variability:

- Process variability results from variations in the process for which the system in question is designed. For example, a slurry pump and pipeline system may be required to convey a range of flow rates, not just a single design value. This is an expected variation and needs to be specified in the design criteria.

- Parameter uncertainty results from deviations in values of input parameters away from design values or design ranges. For example, there may be uncertainty in determination of the rheological parameters of the slurry at various solids concentrations to be used for design of the pump and pipeline system.

\subsubsection{Triangular probability distribution}

Several methods can be used to describe the statistical distribution of input variability. However, a triangular probability distribution (Wadsworth, 1990) can be used to capture historical knowledge and experience of engineers and operators. Figure 1 illustrates how the expected minimum (point A), best estimate (point B), and expected maximum (point $C$ ) values of the input are defined (Janssen, 2005). The triangular probability distribution was used in the risk-based approach presented here. 
Probability Density Function

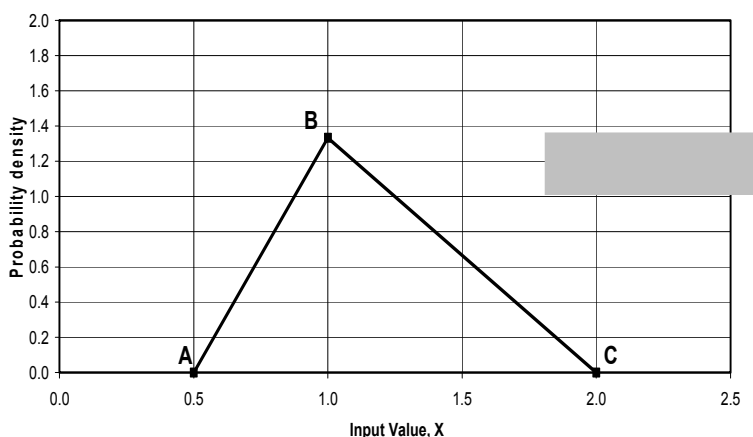

Cumulative Exceedence Probability

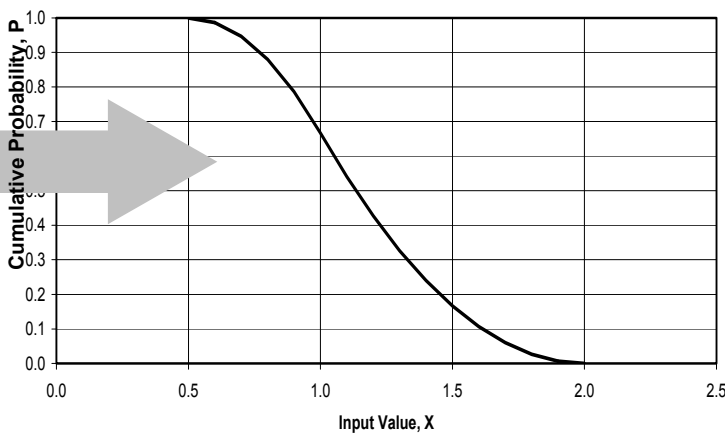

Figure 1 Example plots of probability density function and cumulative exceedence probability for a triangular distribution

\section{$3 \quad$ Launder case study}

\subsection{Design conditions}

The risk-based design approach is illustrated for the design of a rectangular concrete launder for conveying the underflow from a tailings thickener for a copper concentrator. Figure 2 illustrates the dimensions and operating variables for the launder and design conditions for the launder are given in Table 1. Definitions for all parameters are given in Appendix A.

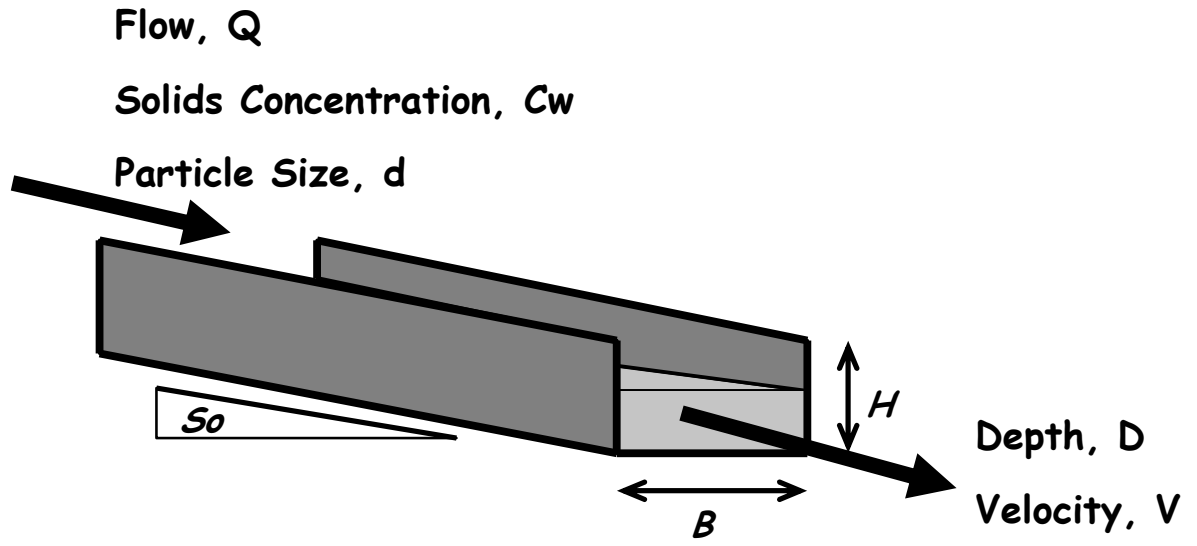

Figure 2 Illustration of launder dimensions and operating variables

Table 1 Design conditions

\begin{tabular}{llll}
\hline Process Conditions & \multicolumn{3}{c}{ Design Parameters } \\
\hline Slurry flow, $\mathrm{Q}$ & $2,628 \mathrm{~m}^{3} / \mathrm{hr}$ & Launder roughness, $\mathrm{ks}$ & $1.5 \mathrm{~mm}$ \\
Concentration, $\mathrm{C}_{\mathrm{w}}$ & $50 \%$ by weight & Solids density, $\rho_{\mathrm{s}}$ & $2,780 \mathrm{~kg} / \mathrm{m}^{3}$ \\
Slurry viscosity, $\mu$ & $100 \mathrm{cP}$ & Liquid density, $\rho_{1}$ & $1,000 \mathrm{~kg} / \mathrm{m}^{3}$ \\
Particle size, $\mathrm{d}$ & $600 \mu \mathrm{m}$ & & \\
\hline
\end{tabular}




\subsection{Performance criteria}

The objectives of slurry launder design are to ensure steady, stable, uniform flow conditions, and to avoid deposition of solids within the launder. To meet these objectives, launders are designed to meet the performance criteria in Table 2, based on the open channel flow relations given in Appendix A.

Table 2 Launder performance criteria

\begin{tabular}{ll}
\hline Criteria & Description \\
\hline $\mathrm{H}-\mathrm{D}>0.5 \mathrm{~m}$ & Freeboard to avoid overtopping of the launder \\
$\mathrm{V} / \mathrm{V}_{\mathrm{L}}>1.2$ & Limit velocity to avoid deposition of solids in launder \\
$\mathrm{Fr}>1.4$ & Froude number to avoid unstable flow \\
$\mathrm{D} / \mathrm{B}>0.3$ & Depth-to-width ratio to avoid meandering within the launder \\
\hline
\end{tabular}

The case study is presented based on Newtonian flow. However, the risk-based design method can equally be used for non-Newtonian flow, and be used to assess the risk associated with variation in the slurry rheology.

\subsection{Launder dimensions}

The first step in the launder design process was a traditional deterministic approach to select the size of the launder to meet the performance criteria in Table 2 under design conditions in Table 1. Launder design was conducted using the open channel flow equations given in Appendix A. The resulting launder dimensions are:

$\begin{array}{ll}\text { Bed slope, } \mathrm{S}_{\mathrm{o}} & 1.2 \% \text { (based on site conditions) } \\ \text { Width, } \mathrm{B} & 0.95 \mathrm{~m} \\ \text { Height, } \mathrm{H} & 1.0 \mathrm{~m}\end{array}$

The launder slope was dictated by site topography, and hence launder width was the only dimension adjusted to change flow conditions. The hydraulic parameters under design conditions are as follows:

Table 3 Launder hydraulic parameters under design conditions

\begin{tabular}{|c|c|c|c|c|c|c|c|}
\hline $\begin{array}{l}\text { Flow } \\
\text { Depth }\end{array}$ & $\begin{array}{l}\text { Hydraulic } \\
\text { Radius }\end{array}$ & $\begin{array}{l}\text { Flow } \\
\text { Velocity }\end{array}$ & $\begin{array}{l}\text { Limit } \\
\text { Velocity }\end{array}$ & Freeboard & $\begin{array}{l}\text { Froude } \\
\text { Number }\end{array}$ & $\begin{array}{l}\text { Depth-to- } \\
\text { Width }\end{array}$ & $\begin{array}{l}\text { Relative } \\
\text { Velocity }\end{array}$ \\
\hline $\mathrm{D}$ & $\mathrm{R}$ & $\mathrm{V}$ & $\mathrm{V}_{\mathrm{L}}$ & H-D & $\mathrm{Fr}$ & $\mathrm{D} / \mathrm{B}$ & $\mathrm{V} / \mathrm{V}_{\mathrm{L}}$ \\
\hline$[\mathrm{m}]$ & {$[\mathrm{m}]$} & {$[\mathrm{m} / \mathrm{s}]$} & {$[\mathrm{m} / \mathrm{s}]$} & {$[\mathrm{m}]$} & & & \\
\hline 0.296 & 0.182 & 2.594 & 1.621 & 0.70 & 1.52 & 0.31 & 1.60 \\
\hline
\end{tabular}

The deterministic design approach has shown that the launder will meet all the performance criteria under the design conditions. However, the deterministic approach does not indicate how sensitive the hydraulic parameters are to changes in inputs, nor does it assess the probability of not meeting the performance criteria. These issues are addressed in risk-based design.

\subsection{Risk-based launder design}

Risk-based design was used to consider failure by overtopping of the launder due to not meeting any of the four prescribed performance criteria. The launder dimensions selected for the design operating conditions were tested for variation in inputs, defined using a triangular probability distribution. 
The risk-based design analysis was conducted by assessing the following parameters:
Fixed launder dimensions
$\mathrm{B}, \mathrm{H}$ and $\mathrm{S}_{\mathrm{o}}$
Variable inputs
$\mathrm{Q}, \mathrm{d}$, and $\mathrm{C}_{\mathrm{w}}$ (and associated $\mu$ )
Output parameters
$\mathrm{H}-\mathrm{D}, \mathrm{D} / \mathrm{B}, \mathrm{V} / \mathrm{V}_{\mathrm{L}}$, and $\mathrm{Fr}$

Based on previous experience with similar mineral processing plants, the variation in operating conditions for the triangular distribution was defined as shown in Table 4.

Table 4 Variation in launder operating conditions, as defined by triangular probability distribution

\begin{tabular}{llll}
\hline & Minimum & Design & Maximum \\
\hline Flow, Q [m3/hr] & 1,800 & 2,628 & 3,000 \\
Concentration, Cw & $40 \%$ & $50 \%$ & $55 \%$ \\
Viscosity, $\mu[\mathrm{cP}]$ & 10 & 100 & 200 \\
Maximum particle size, d $[\mu \mathrm{m}]$ & 400 & 600 & 1,000 \\
\hline
\end{tabular}

Note that viscosity is dependent on concentration, and as such there are only three independent input variables. All other design inputs were assumed to be the same as the design conditions.

\subsection{Operating data}

Measured process data for slurry flow and concentration for the launder in question were available for a period of 45 days. The distribution of the measured flow and concentration are plotted in Figures 3 and 4, respectively. Superimposed on these plots are the triangular probability distribution used in the risk-based analysis, according to the values in Table 4.

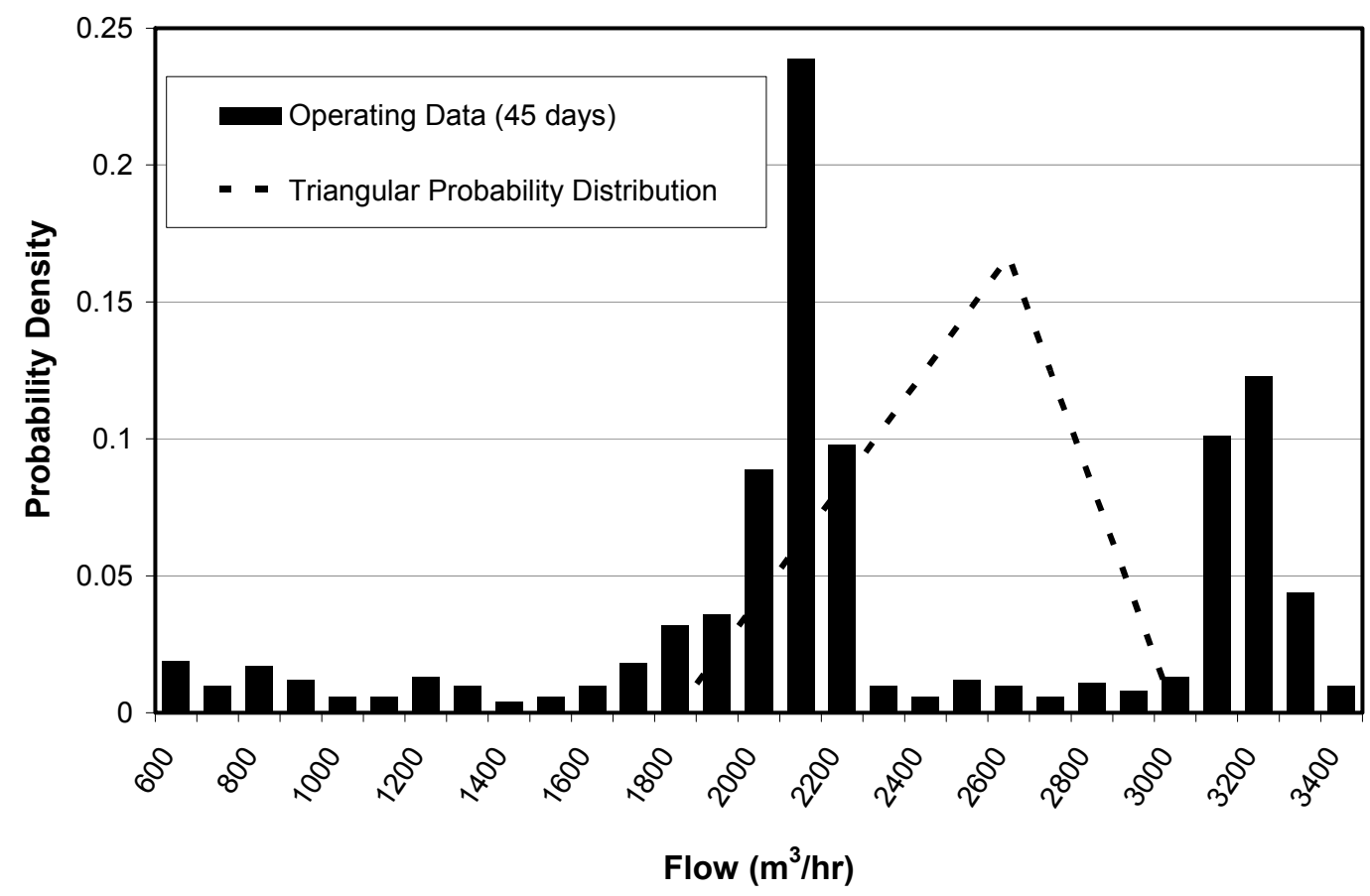

Figure 3 Probability distribution of slurry volumetric flow rate 


\subsubsection{Flow}

The probability distribution of measured flows is shown on Figure 3. This shows a distinct bi-modal distribution, where most of the recorded flow rates are clustered within two distinct ranges of 1,800 $2,300 \mathrm{~m}^{3} / \mathrm{hr}$ and $3,000-3,400 \mathrm{~m}^{3} / \mathrm{hr}$. Although most of the values fall within the range used in the risk-based design $\left(1,800\right.$ to $\left.3,000 \mathrm{~m}^{3} / \mathrm{hr}\right)$, the occurrence of measurements around the design value of $2,628 \mathrm{~m}^{3} / \mathrm{hr}$ was very low.

\subsubsection{Solids concentration}

The probability density distribution of the solids concentration by weight is plotted in Figure 4 . This shows a peak occurrence of concentration of about 51\% solids (compared to a design value of 50\%), and a shape of the probability density function very similar to a triangular distribution. Although the measured concentrations extend outside of the range shown in Table 4 used in the risk-based approach, the majority of the occurrences fall within the range of $45 \%$ to $55 \%$.

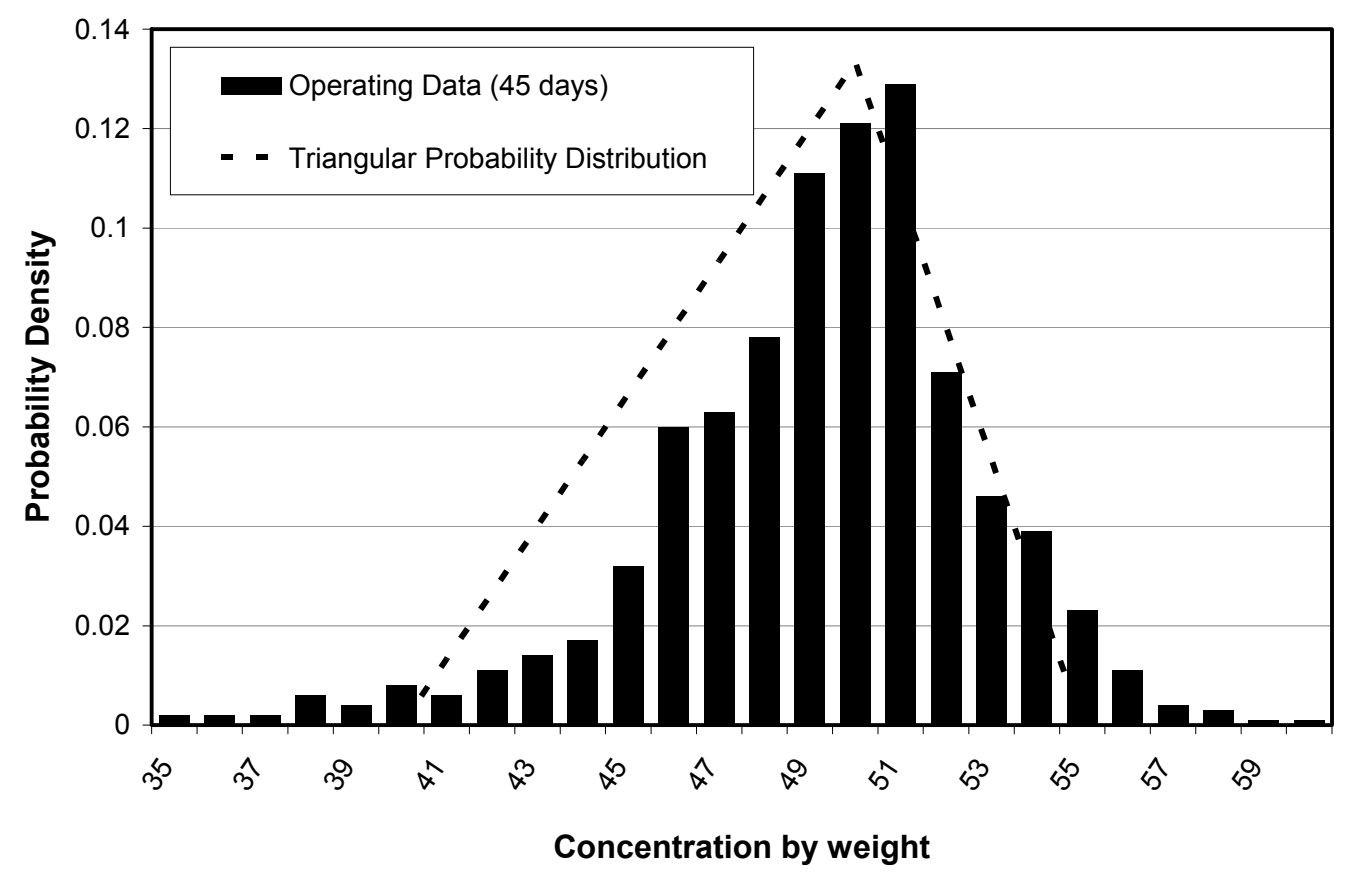

Figure 4 Probability distribution of measured solids concentration by weight

\subsubsection{Viscosity}

The original risk-based design had been conducted for Newtonian flow conditions. Therefore, although rheological tests of slurry samples shown in Figure 5a indicate non-Newtonian conditions, the comparison presented here has been based on Newtonian conditions. The relationship between apparent viscosity at high shear rates $\left(1,000 \mathrm{~s}^{-1}\right)$ and concentration by weight are shown in Figure $5 \mathrm{~b}$. The fitted relationship shown was used to compute apparent viscosities for the calculations based on operating data. Since no further test data was available, the relationship shown was extrapolated to other concentrations.

The variation in launder operating conditions, given by the measured variation in input conditions of flow and solids concentration (and associated viscosity) were compared to the variation modelled in the risk-based analysis. Since no data on the variation in solids particle sizing were available, the design size of $600 \mu \mathrm{m}$ was used in the calculations with measured input data. 
Historic Viscosity Samples

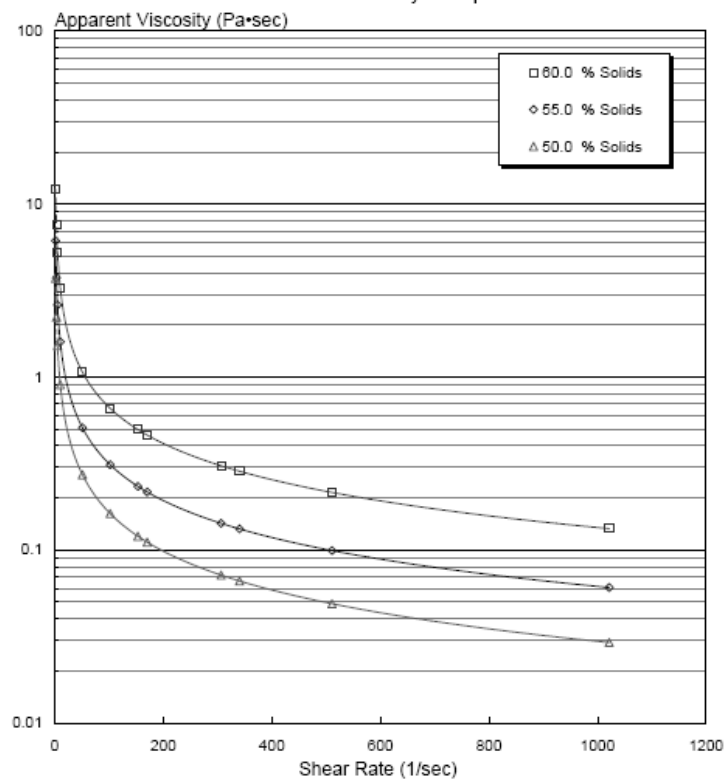

a) Rheology test data of apparent viscosity

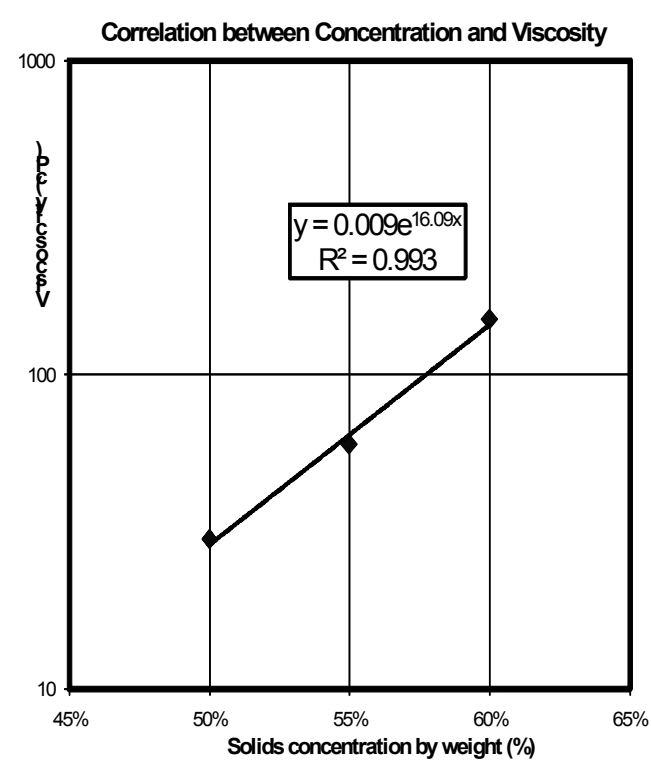

b) Relationship of viscosity to concentration

\section{Figure 5 Measured viscosities}

\section{$4 \quad$ Discussion of results}

\subsection{Risk model - Monte Carlo simulation}

For the risk-based model, a Monte Carlo simulation was used to perform repeated calculations based on the equations given in Appendix A. For each calculation, known as a realisation, the three independent input conditions $\left(\mathrm{Q}, \mathrm{C}_{\mathrm{w}}\right.$ and $\left.\mathrm{d}\right)$ were varied randomly according to the triangular distribution defined in Table 4 . The results of 5,000 realisations performed by the simulation were used to compute the probability of the output hydraulic parameters not meeting the performance criteria. The @ Risk ${ }^{\circledR}$ analysis package (Palisade, 1996) was used with an existing spreadsheet model for open channel launder design to run the Monte Carlo simulation. Use of this approach meant that very little effort was required to set up a risk-based design analysis from the existing deterministic design tools.

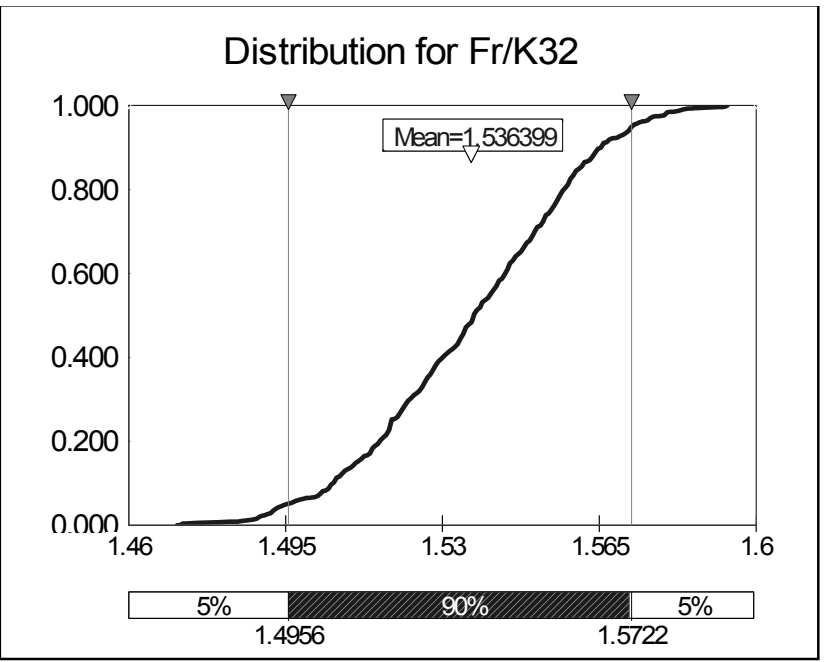

a) Froude number (Fr)

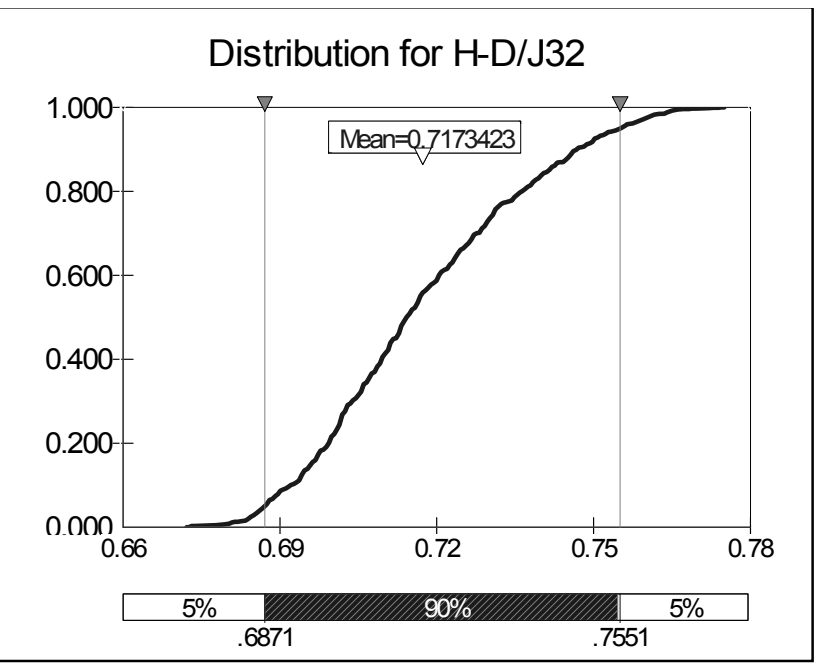

b) Depth-to-width ratio (D/B)

Figure 6 Results of Monte Carlo analysis - cumulative probability distribution 
Figure 6 illustrates cumulative probability distribution plots for the output parameters Fr and D/B. Figure $6 \mathrm{a}$ shows that the Fr does not drop below its minimum criteria of 1.4. However, Figure $6 \mathrm{~b}$ shows that there is a $50 \%$ probability that the $\mathrm{D} / \mathrm{B}$ can drop below its minimum criteria of 0.3 . This resulted in assigning a high likelihood for failing to meet the performance criteria in the FMEA analysis.

\subsection{Simulations with measured results}

2,240 data points of measured flow $(\mathrm{Q})$ and concentration $\left(\mathrm{C}_{\mathrm{w}}\right)$, distributed as shown in Figures 3 and 4, were used to compute the hydraulic operating parameters using the equations in Appendix $\mathrm{A}$. For each concentration, viscosity was computed using the correlation shown in Figure 5. The probability distribution of the 2,240 data points of computed D/B and Fr are shown in Figures 7 and 8, respectively. The results of the risk-based analysis from Figure 6 are also plotted on Figures 7 and 8 for comparison.

The probability distribution for D/B and Fr both show a distinct 'stepped' shape to the curves resulting from the bi-modal distribution of flow rate shown in Figure 3. This behaviour in the input data had not been expected, and was not captured in the triangular probability distribution used in the risk-based analysis.

Figure 7 shows that the risk-based analysis tended to over-estimate the value of $\mathrm{D} / \mathrm{B}$ for most of the probability range. The risk-based analysis estimated a probability of $50 \%$ of not meeting the design criteria of $\mathrm{D} / \mathrm{B}>0.3$, while the measured results indicated that this would occur $65 \%$ of the time. Although the riskbased results for Fr in Figure 8 did not replicate the shape of the measured data results curve, the overall results were generally consistent.

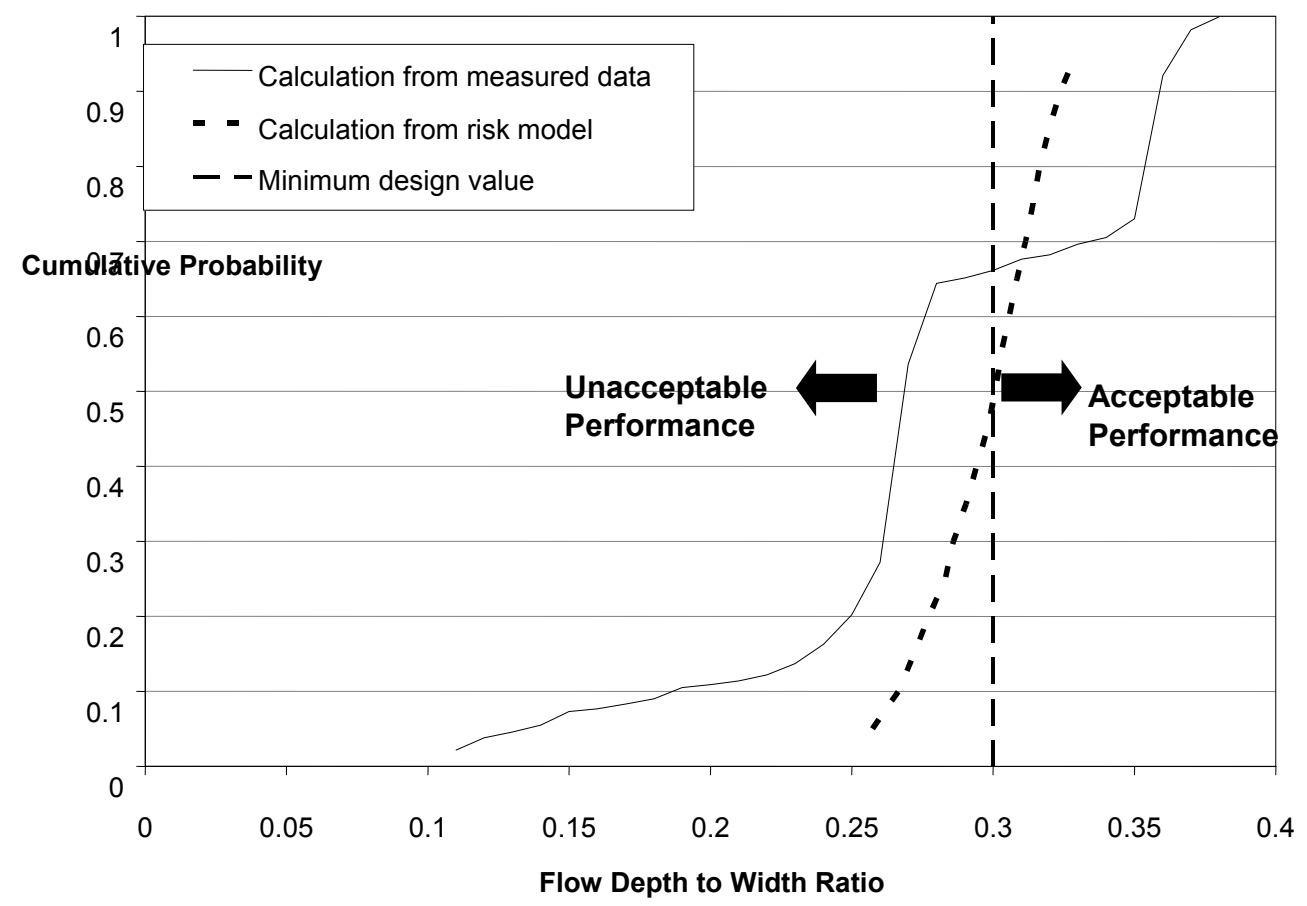

Figure 7 Results of measured data analysis — depth-to-width ratio, D/B 


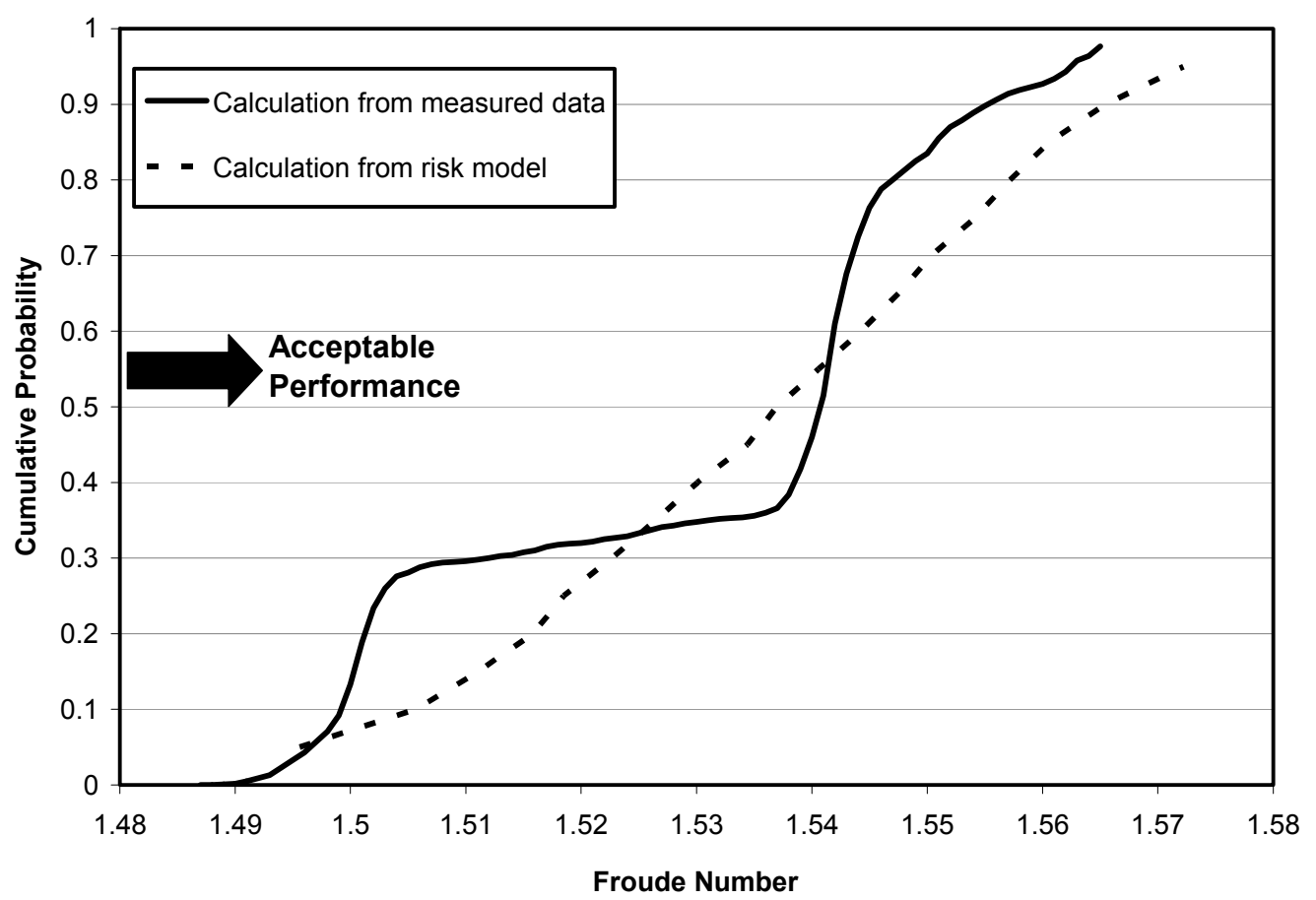

Figure 8 Results of measured data analysis - Froude Number (Fr)

\section{Conclusions}

The fundamental premise of Six Sigma is that any decision analysis is data driven. The results presented in Figures 3, 4, 7 and 8 demonstrate the importance of collecting data to correctly define the variation of the input parameters for a risk-based analysis.

Where the operating data has a single most likely value, such as for the concentration in Figure 4, then the triangular distribution can correctly capture the variation to be used in a risk-based analysis. However, where the operating data is likely to have a more complex distribution, such as the bi-model tendency for flow in Figure 3, this cannot be captured in the usual design criteria of minimum, normal and maximum values. More detail, based on operational simulations or measured data from previous similar projects, should therefore be used in defining the system design criteria. For the risk-based analysis, it will be necessary to identify probability models than can define different behaviours in input parameters.

In spite of not capturing the detailed shape of the measured data, the results of the risk-based design approach presented here still provided a reasonable general description of the potential variation in design output. This can be used in making risk-based decisions for design, operating procedures, and capital investments.

\section{References}

Green, H.R., Lamb, D.M. and Taylor, A.D. (1978) A new launder design procedure. Proceedings of the Annual Meeting of the American Society of Mining Engineers (AIME), Denver, Colorado, 9 p.

Janssen, R.H.A. (2005) Risk based design for water supply infrastructure. Proceedings of the XXXI Congress of the International Association of Hydraulic Engineering and Research (IAHR). Seoul, Korea, pp. 3312-3332.

Janssen, R.H.A. (2007) Risk-based design for slurry launders. Proceedings of the XXXII Congress of the International Association of Hydraulic Engineering and Research (IAHR). Venice, Italy, 10 p.

Palisade (1996) Guide to using @Risk, Palisade Corporation, Newfield, NY, USA, www.palisade.com.

Pyzdek, T. (2003) The Six Sigma Handbook, McGraw-Hill.

Wadsworth, H.M. (1990) Statistical Methods for Engineers and Scientists. McGraw-Hill Publishing Company, H.M Wadsworth Jr. (ed). 


\section{Appendix A - Launder Hydraulics}

Hydraulics of slurry flow in launders is computed using open channel flow equations, as presented by Green et al. (1978).

Table A1 Variable definitions

\begin{tabular}{llll}
\hline $\mathrm{B}$ & Width of launder channel & $\mathrm{S}_{\mathrm{o}}$ & Launder bed slope \\
$\mathrm{C}_{\mathrm{w}}$ & Slurry concentration by weight & $\mathrm{S}_{\mathrm{f}}$ & Hydraulic gradient \\
$\mathrm{D}$ & Slurry flow depth & $\mathrm{Q}$ & Slurry flow rate \\
$\mathrm{d}$ & Design particle size & $\mathrm{V}$ & Slurry flow velocity \\
$\mathrm{Fr}$ & Froude number & $\mathrm{V}_{\mathrm{L}}$ & Critical transport velocity \\
$\mathrm{g}$ & Acceleration due to gravity & $\theta$ & Shields number \\
$\mathrm{H}$ & Height of launder channel & $\rho_{1}$ & Density of liquid \\
$\mathrm{ks}$ & Launder roughness height (rugosity) & $\rho_{\mathrm{s}}$ & Density of solids \\
$\mathrm{R}$ & Hydraulic radius of slurry flow & $\rho_{\mathrm{m}}$ & Density of slurry mixture \\
$\mathrm{Re}$ & Reynolds number & $\mu$ & Slurry viscosity \\
\hline
\end{tabular}

\section{Design Equations for Launders}

Slurry mixture density

$$
\rho_{m}=\frac{1}{\frac{C_{w}}{\rho_{s}}+\frac{\left(1-C_{w}\right)}{\rho_{l}}}
$$

Reynolds number

$$
\operatorname{Re}=\frac{4 R V \rho_{m}}{\mu}
$$

Friction factor using the Swamee-Jain approximation to the Colebrook-White equation:

$$
f=\frac{0.25}{\left[\log \left(\frac{k s}{14.8 R}+\frac{5.74}{R e^{0.9}}\right)\right]^{2}}
$$

Hydraulic gradient using Darcy-Weisbach formula:

$$
S_{f}=\frac{f}{4 R} \frac{V^{2}}{2 g}
$$

Minimum limit transport velocity combining Darcy-Weisbach and Shields number:

$$
V t=\sqrt{\frac{8 \theta g d\left(\rho_{s}-\rho_{l}\right) / \rho_{l}}{f}}
$$

Minimum Shields number to avoid deposition in launder:

$$
\theta=0.8
$$

